\title{
PEDRO COSTA ENTRE O DEVIR COMUM E O DEVIR IMPRÓPRIO: POSSIBILIDADES PARA PENSAR A SINGULARIZAÇÃO DE COMUNIDADES MÍNIMAS COM O FILME JUVENTUDE EM MARCHA
}

\author{
Breno Isaac Benedykt ${ }^{1}$
}

Resumo: Ao percorrer o conceito de devir na obra de Gilles Deleuze e, mormente, após seu encontro com Félix Guattari, sentimos que este, dado à sua crescente abrangência e dinâmica cada vez mais ramificada, caminha sentido uma nova noção de imagem como produção de singularizações as quais despossuem o homem de seus limites organizacionais em forças anômalas. Em um texto decisivo, 1730 - Devir-intenso, devir-animal, devir-imperceptível... encontramos a reapropriação da noção de anômalo, oriunda dos escritos de Georges Canguilhem, para construir o elo entre o devir-animal e os grupos (ou povos) minoritários oprimidos, proibidos, revoltados, periféricos -: traço nevrálgico para pensar o cinema de Pedro Costa. Porém, é em conexão com Maurice Blanchot que essa dimensão problemática da experiência do devir ganha fôlego e dá consistência a uma dobra comunitária. Não se trata mais do anômalo solitário, como borda da matilha, mas do comum impróprio como dobra em individuação. Deleuze em ao menos dois momentos chega a remeter-nos a uma possível relação entre devir e comunidade, mas pouco a explora. Num primeiro momento, em Cinema II: A Imagem-Tempo, ao tratar dos filmes de Jean Rouch e Pierre Perrault, e, mais adiante, em seu ensaio Bartleby, ou a fórmula. Tendo isso em vista, é no arranjo entre seu pensamento (e de Guattari) e o de Blanchot que desenvolveremos uma linha capaz de dar expressividade filosófica à experiência arrebatadora que o cineasta Pedro Costa nos apresenta em seu filme Juventude em Marcha. No filme, seguimos uma personagem, Ventura, a qual, sem deixar de operar uma individuação excepcional, jamais cessa de desfazê-la em linhas afectocomunitárias. Assim, entre a escrita, a voz e a imagem, na penumbra de espaços e tempos díspares, encontramos a atualização de comunidades mínimas, as quais revelam sua força imprópria e, portanto, não identitária.

Palavras-chave: Comunidade; devir; Gilles Deleuze; Pedro Costa.

Se vemos poucas coisas numa imagem é porque não sabemos lê-la, por que avaliamos tão mal a rarefacção como a saturação. (DELEUZE, 2009, p. 30)

\begin{abstract}
Cuando Griffith encuadra un talud, un poste eléctrico y una vía férrea debajo, se vulve una imagen misteriosa y, al mismo tiempo, es una imagen absolutamente realista. Si uno no es capaz de lograr esta alianza de realismo y de misterio, es mejor no ponerse a hacer ninguna imagen. (HULLIET apud COSTA, 2011, p. 102)
\end{abstract}

\section{Introdução}

Antes de mais nada, é relevante termos em vista que o trabalho analítico que desenvolveremos com o filme Juventude em Marcha de Pedro Costa e sua intersecção com o

\footnotetext{
${ }^{1}$ Doutorando em Filosofia na Universidade de São Paulo. Bolsista FAPESP, número do processo: 2018/03080-9.
} 
problema filosófico do comum, se situa em dois níveis. Podemos dizer que por um lado se trata de uma análise no nível da forma fílmica, incluindo tanto a disposição e a presença de suas personagens num determinado espaço como os usos do som e suas composições, além da montagem e do enquadramento. Entretanto, uma análise restrita a esse nível não bastaria para acessar a virtualidade conceitual de suas imagens, o que faz necessário uma entrega sensível a outro nível analítico, o qual - é preciso ter isto em mente - não exclui o anterior, mas tem a particularidade de pensar no plano das forças ou das intensidades, isto é, de ver a forma como quantuns de força e como efeitos de intensidade. Por fim, vale acrescentar que para compor nossa análise levaremos em conta o procedimento e a experimentação de Pedro Costa ao longo de todo o processo.

Além disso, por partirmos de uma perspectiva crítica à noção clássica de representação, entendida como referencialidade a uma verdade (ou realidade) externa ao ato de criação e ontologicamente primeira em relação a ela, nos endereçamos, junto com Deleuze, ao filme Juventude em Marcha concebendo-o como um bloco de imagem capaz de exprimir, mais do que representar ou traduzir, a verdade de um ser-do-devir. Nesse sentido, desde o nosso ponto de vista, o mais interessante e radical de Juventude em Marcha são os devires nele expressos e com os quais nos vincula, e não tanto a leitura de que se trata de uma documentação estética da vida de imigrantes cabo-verdenses em Portugal - ainda que não esteja excluída a possibilidade de entendê-lo enquanto tal. Entretanto, os limites estabelecidos pelas exigências de uma caracterização representativa da imagem, reduzem a experiência fílmica a um mero documento comunicacional, perdendo de vista as relações problemáticas - quero dizer, pensantes - da imagem.

É apenas por meio do enfrentamento de relações não recognoscíveis e, portanto, de difícil perceptividade que podemos levar adiante uma análise implicada com os devires (por vezes, abismal) do filme. Nesse sentido, uma análise atenta ao devir da questão comunitária deve evitar as noções clássicas que a enclausuram em noções tais como as de comunhão religiosa ou de vínculo identitário (filiação familiar, substancial ou linguística), as quais além de pressupor um horizonte homogêneo de paz perpétua, fazem do comum uma experiência reduzível às dicotomias do normal e do patológico, do social e do individual, do familiar e do desconhecido, grosso modo, às dicotomias do mesmo e do outro. Mas, indo além, é possível dizer que tais concepções assujeitam as experiências do comum, via uma necessidade arbitrária que nos limitam a pensá-las exclusivamente pela ordenação do que lhe é interno e externo, fechando, essa própria dicotomia à imanência de experimentações que escapam à aos termos de uma relação referenciada a um Uno (historicamente variável) suprassensível, o qual, não apenas excluí, mas combate a realidade dos devires.

Tal problemática exige, portanto, uma modificação do olhar, isto é, um desvio em nossos órgãos perceptivos. Não basta reconhecer os fatos, saber que aqueles corpos existentes nos filmes de Pedro Costa são corpos em condições de extrema vulnerabilidade, é preciso ver a imagem-vidente de seu cinema. Pois ela excede a percepção da situação, ela vê o que o clichê pré-configurado em nossas condições sensório-motoras cotidianas são incapaz de ver. Diante de Juventude em Marcha não estamos mais prontos para reconhecer as situações sociais e a reagir a elas; não vemos apenas uma questão de fato (quid facti), vemos as forças vitais de uma questão de direito (quid juris).

\section{Primeiro olhar}

Nos filmes de Pedro Costa, é preciso assumir, não vemos seres e situações de fato, mas um devir, por vezes, abismal. E é o próprio Pedro Costa (2011) que nos revela como sua percepção entrou em crise diante de Fontainhas, forçando-o a restabelecer todos seus vínculos com o cinema, consigo mesmo e com o mundo. 
Além da necessidade de abandonar suas antigas parcerias, modificando significativamente o modo como costumava trabalhar, Pedro Costa $(2011$, p. 26) conta que para fazer um "enquadramento, um texto pelo qual as pessoas iam falar (...), iam inventar", , tornouse necessário ver a distância, isto é, ver esse "buraco entre nós, o qual ia fazer o filme, e não outra coisa". Não bastava reconhecer a condição social daquelas pessoas, era preciso escutálas, vê-las, viver em Fontainhas, pois era assim que essa distância passava a ser visivelmente real. Inclusive, nos conta Pedro Costa (2011), a ideia de seu ato de criação é inseparável do que lhe veio na experiência radical de entrar, por acaso, em Fontainhas. Como ver, pensar e filmar esse the other half ${ }^{3}$ ? Essa era a questão que lhe tocava e que lhe mobilizava a encontrar uma linha de sensibilidade comum entre ele e essa "outra metade", por meio da qual Pedro Costa não seria mais o português, com sua percepção de colonizador, e nem aquelas pessoas, os miseráveis e adictos de Fontainhas. "Era uma tentativa de organização de nossas sensibilidades, de ver como nossa sensibilidade, nossos sentidos, nosso aparelho sensitivo tocava o de Vanda" (p. 148), isto é, de que modo a linha sensitiva de Pedro Costa passava a ressoar com a linha sensível daquelas personagens-reais: Vanda, Ventura e outros. Assim, as coisas não estariam mais no nível de um documentário (em seu sentido bruto, de representação de uma verdade dada por antecedência), pois nem mesmo a câmera se encontrava mais nessa posição de simples mediador entre termos. Ela passava a ser a única capaz de aprender essa passagem entre eles, essa distância, esse buraco, o qual o cineasta passou a chamar de uma sensibilidade comum.

Ora, essa distância é justamente a relação singularizante que confronta a câmera, o diretor e as personagens de Fontainhas a atingir a fabulação de um espaço-tempo que excede suas relações empíricas e pragmáticas. Como fazer da imagem, dos gestos corporais e dos atos de fala a fabulação dessa distância? Pedro Costa sabia que isso só seria possível se ultrapassasse (e com ele sua câmera e as personagens), o nível das existências de fato, para afirmar o direto de existir dessa distância singular, sensível e real que constituía o encontro entre eles. Não se tratava, portanto, de julgar ou de interpretar (no sentido de um saber externo), mas de tornar visível as intensidades dessa distância que antecedia a verdade de cada termo no encontro.

O desafio, portanto, era fazer visível essa variação afetiva, essas relações de velocidade e de lentidão que atravessam esse buraco, essa distância, em suma, de filmar uma relação singular. Longe de um olhar neutro sobre aquelas pessoas, o cinema de Pedro Costa exprime a tomada de posição de uma imagem que abandonou os limites de uma percepção espaçotemporal a fim de criar a imagem-testemunha de um devir entre elas.

David Lapoujade (2017, p. 22), explicou de modo brilhante em seu livro As existências mínimas de que modo a "testemunha nunca é neutra ou imparcial. Ela tem a responsabilidade de fazer ver aquilo que teve o privilégio de ver, sentir e pensar"; o que faz de sua tomada de posição algo bastante próximo da figura filosófica do advogado, o qual se afasta da posição do legislador, que julga e justifica, e passa para a posição daquele que contrai as forças de uma singularidade para defendê-la e expandir sua existência.

\section{Segundo olhar}

Ao percorrermos o conceito de devir na obra de Deleuze e mormente após seu encontro com Félix Guattari, é possível notar como esse conceito possibilita alojar no interior o problema do comum, entendendo-o como uma experiência de singularização anômala. Em um texto de

\footnotetext{
${ }^{2}$ Todas as traduções de Pedro Costa (2011) são realizadas livremente por nós desde uma versão em espanhol.

${ }^{3}$ Termo utilizado pelo fotografo Jacob Rii para se referir às pessoas às quais se dedicava fotografar. Pedro Costa (2011) retoma o termo conscientemente, por ver na expressão um olhar sensível a essa multidão de excedentes que o capitalismo produz.
} 
Mil Platôs, Deleuze e Guattari (2012), buscando expandir as conexões de seu conceito de devir, trazem à tona o conceito de anômalo oriundo dos escritos de Georges Canguilhem (2015), percebendo-o como uma via vitalista que permite pensar a singularização flutuante de experimentações existências quase sempre imperceptíveis e, no entanto, absolutamente imanente à vida. Tal conceito substitui, sem desconsiderar os efeitos reais da dicotomia organizacional, invariável e transcendente, de categorias pautadas na distinção moral entre o normal e o patológico. O anômalo é devir, isto é, uma nova relação impensável entre o corpo e o meio, entre o mundo e o ser individuado, a qual exprime uma verdadeira busca involuntária para solucionar uma problemática ao mesmo tempo real e vital (ainda que virtual), a qual antecede e excede as coordenadas biopolíticas ou psicossociais que circundam o universo moralizante de relações contratuais e de interdependência entre termos em posições pré-fixadas - tais como a do médico e do paciente, do doente e do saudável. Como observava Canguilhem (2015), enquanto o normal e o anormal pertencem à ordem cronológica do campo social, a anomalia corresponde à diferenciação permanente de uma experiência vitalista mormente imperceptível às partes, pois se faz nos limites de uma relação infinitesimal com o meio. Experiência desviante, irregular e rugosa, como a caracteriza Canguilhem (2015), ela que se opõe à regularidade lisa e homogeneizante do normal e anormal.

Ao retomar tal conceito e conectá-lo ao de devir, Deleuze e Guattari (2012) lhe dão uma dimensão estética e política, a saber, como uma potência criativa que de direito (quid juris) pertence aos grupos (ou povos) minoritários - oprimidos, proibidos, revoltados, periféricos -, na medida em que fabulam esse comum germinativo por meio distâncias variáveis entre individuações não previamente correspondentes. Não nos parece de pouca relevância que em Juventude em Marcha exista inúmeras retomadas e, dentre elas, as emblemáticas recitações da última carta do poeta Robert Desnos escrita desde um campo de concentração e endereçada à sua esposa Youki, em 15 de julho de 1944. Ventura a recita várias vezes e a cada vez, com pequenas diferenças, uma diferença profunda parece ganhar intensidade. É essa distância, essa sensibilidade comum que não pertence mais a Robert Desnos do que a Ventura. A carta não tem mais proprietários, nem propriedades, tornou-se um coletivo de enunciação: carta-mundo, carta-testemunho, distância comum entre individuações não-correspondentes, singularização que cabe à câmera testemunhar.

O problema da relação mudou ao mesmo tempo em que os limites previsíveis e espaciotemporais entre o destinatário e o remetente também se transformar, o termo virou efeito e o meio o antecedente, e a relação envolvida na carta, relação de relações.

\section{Terceiro olhar}

Lembremos como começa o filme. A câmera fixa, um leve contra-plongée e diante de si e de nós, um espaço qualquer, certamente singular: uma favela qualquer, a qual, como toda favela, expõe suas ruínas e oferta ao olhar o desaparecimento do espaço euclidiano para a exposição uma relação pouco típica, limite, possível, com o espaço. Há poucas cores, digamos que apenas o suficiente para vermos a construção precária de suas casas. Nele não há horizonte visível e as bordas do plano fixo estão escuras. Surge aos poucos a crescente sensação de que aquele espaço vive sob as forças do fantasmático, não por alusão a fantasias subjetivas, mas pela sensação de permanente movência exposta por essa imagem ao mesmo tempo distinta e obscura. É uma imagem capaz de provocar, sem qualquer apelo à lógica do suspense ou do terror, um estranhamento radical. A percepção recognoscível se desfaz aos poucos e a imagem revela ser o germe de um ambiente de seres reais e fantasmáticos. Nele e frente a ele o corpo ativo parece dissipar-se - não há susto, nem lágrimas -, ao mesmo tempo em que o pensamento, supostamente passivo, conquista uma atividade anômala. Há um hibridismo paradoxal 
simultâneo à imagem, ao ambiente e ao nosso olhar; tudo é passivo e, no entanto, há uma visível sensação de forças ativas. É o início de uma experiência de intensidades sem destino claro, a qual se dá nessa distância entre a câmera e as casas. Deleuze (2009, p. 218) outrora nos falou de uma experiência "impassiva", a qual, nem ativa e nem passiva, seria a realidade de uma sensação de incessante passagem entre as duas - o germe que é o afecto sem-sentido.

Ainda nesse mesmo plano-sequência surge de uma de suas janelas um corpo sem contorno. Escurecido pelas sombras e pela pouca luminosidade do ambiente, só é possível ver o gesto repetitivo pelo qual esse corpo arremessa uma série de mobílias pela janela, as quais, por sua vez, ao caírem no chão, produzem o barulho que se propaga pelo ar ao modo de uma energia nascente. Não é o vazio, mas a precariedade viva de uma serenidade que começa a germinar, a qual encontraremos nas personagens do filme, afetando todas as suas narratividades e, num só tempo, fazendo com que sua estrutura trôpega nunca coincida com a narratividade do cinema tido clássico: situação, solução (ou reviravolta) e desfecho.

Não à toa, nesse momento do filme se impõe a sensação de estarmos diante de um quadro de natureza morta, pelo qual se exprime: "devir, mudança, passagem” (DELEUZE, 2005, p. 27), mais do que um suposto vazio a prefigurar uma narrativa histórica. Como no cinema de Yasujiro Ozu, trata-se de um universo no qual o vazio é apenas o correlato de objetos e de personagens que vivem e falam com vagueza na plenitude de suas composições possíveis, visível graças ao delicado enquadramento de um plano fixo. Pedro Costa (2011, p. 83), numa longa conversação com Andy Rector, nos diz que em seus filmes o plano fixo tem como função tornar visível tudo aquilo que se move, ainda que seja apenas a movência do ar: se o quadro fixo tem alguma relevância é por "dar ao espectador a liberdade para perceber" tudo aquilo que se move, mesmo quando esses movimentos são infinitesimais, quando parecem acontecer apenas "na cabeça e nos olhos" do espectador. Trata-se, podemos dizer, de uma distinção ao mesmo tempo estética e política entre aquilo que somos capazes de ver ordinariamente e aquilo que seu cinema se esforça por fazer visível e sensível - o ato de criação de um povo ou de um comum que nasce essa distância intensiva.

Recordemos como Deleuze (2009) deu especial atenção ao enquadramento cinematográfico, concebendo-o ao modo de uma semente fechada em sua previsibilidade ou, por outro lado, ao modo de um germe conectado ao cosmos - a depender se sua relação com o forade-campo. "Pode dizer-se do plano que ele age como uma consciência. Mas a única consciência cinematográfica não somos nós, cada um dos espectadores, nem o herói, é a câmera, ora humana, ora inumana ou sobre-humana" $(2009$, p. 40). Quanto mais tênue é o fio que conecta o quadro à exterioridade do mundo maior é a distância intensiva conquistada pela câmera em relação ao fechamento geométrico e à seleção limitante da consciência humana. A força do enquadramento dinâmico, que perpassa o início do filme Juventude em Marcha, é justamente essa: fazer com o que o enquadramento atinja a qualidade do impróprio, entendendo-a como uma potência compositiva que pode exceder a realidade mental que costuma assujeitar o olho da câmera aos limites do bom-senso de uma boa consciência humana e ao senso-comum de uma subjetividade fechada em si mesma (seja ela vista pelo seu ângulo objetivo ou subjetivo). É por estar situada fora dos termos que a Relação pode descobrir os fios de uma imagem conectada à multiplicidade amorfa de comum impróprio, mas também é justamente por isso ela pode cair nas coordenadas de olhares clichês que não lhe pertencem $a$ priori.

No entanto, há aí toda uma positividade do enquadramento entendido como Relação impessoal, na medida em que ela permite pensar a existência de vínculos para além da previsibilidade do que pode a consciência humana. Como diz Deleuze (2009, p. 25), a primeira ressonância do cinema com a filosofia de Henri Bergson é justamente essa: "Se se tivesse que definir o todo [- em seu sentido bergsoniano - ] ele seria definido pela Relação. É que a relação 
não é uma propriedade dos objetos, ela é sempre exterior aos seus termos. Além disso é inseparável do aberto e apresenta uma existência espiritual ou mental”.

\section{Quarto olhar}

Todo enquadramento de Ventura (personagem principal de Juventude em Marcha), nos afasta de uma concepção relacional ao modo contratualista. Ventura sozinho ou em companhia de outras pessoas, nunca compõe uma soma de corpos com elas como se estivessem circunscritos a uma situação espaço-temporal e uma posição psicossocial. O enquadramento dos corpos e dos atos de fala em Juventude em Marcha tensionam permanentemente os limites previsíveis de uma situação facilmente codificável. São gestos que exprimem a plenitude de corpos menos presos à sua funcionalidade orgânica do que entregues à descoberta de diferentes posições, enquanto as falas exploram camadas misteriosas do um passado que não se rende aos limites de uma história pessoal. Assim, quando não é o corpo que se desvencilha das funções organizacionais a ele previstas é a fala que se desconecta do seu entorno, revelando relações que perpassam e ultrapassam o plano atual em que se encontram.

Reagir à situação seria manter o corpo e a fala de Ventura, e daqueles com quem se encontra, presos às coordenadas de uma condição pessoal, mas em Juventude em Marcha toda e qualquer coordenada sensório-motora parece desmoronar: o espaço, mas também o corpo e a fala exprimem vínculos com linhas verdadeiramente virtuais, o que está em torno, o atual, não é capaz de revelar a luz que descobrem essas distâncias virtuais. Distâncias muito mais misteriosas do que toda virtualidade um passado pronto ou programado para se atualizar, a depender apenas das exigências externas do que se percebe em seu entorno. Não à toa, o vagar do corpo e potência das falas introduzem relações longínquas, as quais ao mesmo tempo em que mostram sua intensidade incomum, paradoxalmente, dizem de um comum que nos escapa: impassivel distância que os atravessa.

Pedro Costa (2011, p. 97), outra vez, se próxima de Ozu e nos recorda como "Ozu não fazia distinção entre o mar e um sapato, um homem e as nuvens. Havia correspondência entre as formas". Talvez o melhor seja dizer que a correspondência não previsível entre as intensidades dessas formas é que fazia de sua câmera uma consciência inumana ou sobrehumana, capaz de dar-lhes, ou melhor, de captar, essa correspondência impensável para uma consciência demasiado humana, esse afecto ou hiato que nasce entre os termos. Fazer sensível essa distância para o pensamento talvez seja o principal aprendizado de Pedro Costa com Ozu - dar a ver o devir, essa relação (in)comum, essa passagem incessante entre algo perceptivelmente comum e, no entanto, visivelmente incomum. Como em Ozu, não tampouco há necessidade de mover a câmera para o enquadramento dá passagem a essas intensidades. No entanto, em Pedro Costa tudo muda à medida que suas personagens são personagens-reais e seu filme nunca deixa de relevar algo que também lhe acontece. Mostrar a força sútil de uma fantasmática realidade a deslocar seu presente.

Há algo nisso tudo de desobediente. Não apenas em Ventura, mas na maior parte dessas personagens-reais, mas o que elas desobedecem é inimitado. Há como que uma desobediência absoluta sem nunca dar a ver uma oposição direta à ordem. É a desobediência que não opera pela dicotomia entre a regra e a exceção, não combate um termo com seu oposto, mas exprime posições e atos de fala de uma recusa, ou melhor, de uma preguiça que não quer deixar de fabular. Não desobedecer para desobedecer melhor, mas também não obedecer, para desobedecer de outro modo.

Recordemos do plano em que Ventura está apoiado na parede de um museu entre dois retratos da elite europeia dos séculos XV e XVI. Ventura ocupa a distância entre um retrato realizado pelo 
pintor Anthony van Dyke e outro por Peter Paul Rubens. Trata-se de uma imagem que coloca essa personagem-real num lugar igualdade com esses outros corpos retratos. Entre os três, como num quadro barroco, há devir, mudança, passagem. Por isso, se a sensação num primeiro momento é de que Ventura está tão presente e tão ausente quanto as personagens retratadas pelos pintores do século XV e XVI, um outro olhar acaba por revelar como o corpo de Ventura expõe em si mesmo uma intensidade que o destaca em relação aos outros. Ele é essa imobilidade móvel entre os outros dois. Ele perturba, ele exprime esse devir minoritário que os outros não são capazes de ver e de sentir. Ventura transforma-se em passagem e faz real essa distância de um corpo feito de gestos, o qual excede o plano dos corpos sólidos, organizados e idealizados nos belos retratos daquela elite colonial. Eé por ser corpo perturbante que será coagido a se mover no espaço; a fazer do movimento intensivo, movimento extenso. E, em seguida, aquele cujo corpo se assemelha ao seu, talvez um de seus filhos, irá limpar o chão sobre o qual pisou.

Mas se Ventura se diferencia num plano que pareceria mostrar uma igualdade entre diferentes, como entender esse comum que corta o filme e o distingue das tentativas de o circunscrever à normatividade social? Como entender como sendo uma comunidade essa desobediência passiva a toda tentativa de inclusão de seu corpo, de seus gestos, de seus atos de fala, em uma situação de paridade e conformismo social?

Vale lembrar como Ventura recusa os apartamentos que o corretor de imóveis lhe apresenta. A boa vontade de um não se aproxima nem de perto ao estado de pensamento do outro. Ventura não apenas recusa, mas o faz de modo singular. Cria o gesto de sua recursa, faz ver, faz perceber, capta e exprime algo que sempre escapa ao corretor de imóveis.

\section{Quinto olhar}

Em outro plano, Ventura aparece junto com uma dessas personagens com as quais ao longo do filme vive enigmáticas relações de aliança. Trata-se de uma mulher com quem se põe a observar uma parede que está fora-de-campo. Sentados numa espécie de cama/sofá improvisado no chão, ambos falam do que vem surgir nessa parece cega. É como se estivessem olhando para um filme numa tela branca posta fora-de-campo. O que vemos são espectadoresreais que se deslocaram, ainda que permaneçam sendo os personagens-reais do filme. Outro hibridismo, dessa vez que faz coexistir essas duas posições em simultaneidade em uma relação entre imagens. Suas falas multiplicam os corpos e as posições de tudo que estão vendo, mas também de tudo o que nós vemos. Não é apenas a parede que aboliu as referências, são as próprias personagens que se converteram em pura superfície sem qualquer tipo profundidade para o acomodamento de clichês. Só há passagem e distância, verdadeiro devir cujo acontecer se faz em contato com uma exterioridade radical em relação às organizações sociais e perceptivas de sujeitos previsíveis em um dado espaço. Tudo vem de outro lugar, de distâncias, de coexistências não-correspondentes, por vezes, paradoxais ou impensáveis.

Aqui entramos em um aparente impasse, pois Deleuze pouco conectou, ao menos de modo explícito, o conceito de devir ao de comunidade ou de comum. Em um dos momentos mais emblemáticos no qual surge uma possível conexão entre esses conceitos é no rico e complexo ensaio, Bartleby: ou a fórmula (DELEUZE, 2011). Como é sabido, Deleuze toma a expressão preferiria não, e sua função-limite em relação à língua inglesa, como ponto de partida. É pela literalidade intensiva desta fórmula e pelo seu abrupto aparecimento que ela é capaz de fazer com que uma atmosfera cômica e enlouquecedora tome conta de todo o escritório de advocacia. Se ela é literal e funciona como uma língua estrangeira, ou de modo agramatical, como Deleuze sugere, é por criar um germe capaz de exprimir uma Diferença interna a esta Relação cuja abertura, fechamento e movência se situa sempre algures. É essa diferença que irá 
perpassar todos os corpos como uma exterioridade radical em relação aos termos agenciados, neste caso, o advogado, os outros escreventes, a disposição dos objetos e dos corpos no escritório, Nova York, a revolução americana com seu anarquismo e, por fim, a luta de sua literatura contra a razão neurótica do velho mundo; sua função paterna, sua filantropia e sua caridade. É por atingir a superfície desse limite que a fórmula põe em xeque toda a organização desses elementos, funcionando ao modo de um tensor incessante e insaciável. Como nos diz Deleuze (2011, p 92), é a expressão de "uma anomalia" contagiante, não tanto por uma adesão voluntária quanto por um contágio imprevisível.

Ora, o ponto central que mais nos interessa aqui é sobretudo o fato de que essa relação tampouco pertence a Bartleby, ao menos enquanto sujeito circunscrito à gramática social. Bartleby, insiste Deleuze (2011, p. 94) - e aqui poderíamos falar algo de similar a respeito de Ventura -, é quem recusa a condição de particular: "qualquer particularidade, qualquer referência é abolida", e é isso que faz crescer sua potência, ou melhor, esta força tensionadora das posições sociais. É essa potência que dá a Bartleby o direito de "permanecer imóvel e de pé diante de uma parede cega. Pura passividade paciente, como diria Blanchot" (DELEUZE, 2011, p. 94) ou ainda, se quisermos, paciência ativa de um gesto de passividade criativa.

Também é por meio dessa força singular de Bartleby e outras personagens de Herman Melville que Deleuze desemboca na ideia de que este devir ilimitado traz consigo um novo tipo de comunidade, uma comunidade de alianças que substitui àquela das filiações neuróticas fazendo-as, inclusive, passar pela loucura de vínculos impróprios: "um irmão, uma irmã”, ou ainda, como vemos em Juventude em Marcha, um filho ou uma filha, ou até mesmo um pai ou uma mãe, tanto mais verdadeiros quanto não pertencem a ninguém, "já que toda 'propriedade' foi abolida" (2011, p. 111). Deleuze se pergunta então: "Como essa comunidade poderia realizarse?” (2011, p. 111). Ora, a resposta de Deleuze (2011) não poderia ser mais precisa, mais imanente. O problema já está resolvido em si mesmo, na mediada em que essas personagens não introduzem um tema individual, mas um assunto coletivo, fundando um "um muro de pedras livres, não cimentadas, onde cada elemento vale por si mesmo e no entanto tem relação com os demais" (2011, p. 113). É por meio dessa perspectiva que podemos dizer as personagens de Pedro Costa em Juventude em Marcha aparecem como um verdadeiro testemunho de uma enunciação coletiva, desse "povo por vir", "desse devir humano" (DELEUZE, 2011, p. 117).

Pedro Costa é outro na medida em que Fontainhas, Vanda ou Ventura, não são mais apenas Fontainha, Vanda ou Ventura, a distância é passagem, mudança, devir. A lógica dos pressupostos foi desmoronada ao mesmo tempo em que a consciência da câmera fundava um novo povo, um novo comum, ainda que instantâneo, com seu mínimo volume.

\section{Fechamento}

Se nem Ventura, nem as outras personagens do filme e tampouco Pedro Costa ou sua câmera podem ser qualificadas como indisciplinares em relação às regras sociais, nem por isto elas deixam de exprimir um desvio ou uma série de desvios radicais. Uma relação verdadeiramente anômala por originalidade. Como escreveu Blanchot (2013) a respeito dos amores mais repugnantes, num diálogo original e intenso com o conto de Marguerite Duras, A doença da Morte: "Lá onde se forma uma comunidade episódica (...) se constitui uma máquina de guerra ou, para melhor dizer, a sensação da possibilidade de [destruição de nossa organização social], a qual porta em si, mesmo que em dose infinitesimal, a ameaça de sua aniquilação" (BLANCHOT, 2013, p. 67).

Ora, não é justamente essa a paradoxal função daqueles que traçam no mundo uma relação para além de nossos pressupostos? Isto é, criar o impossível a partir do possível? Como já atentava Georges Canguilhem, o anômalo é mais excesso de vida do que um deficit. Assim, se 
o "anormal", como falavam Deleuze \& Guattari (2012, p. 26), "só pode se definir em função das características, específicas ou genéricas; o anômalo [... por sua vez, é] a aliança". Mas então, como testemunhá-la? Como dar-lhes o direito de existência? Não é essa a questão que coloca de Pedro Costa numa linhagem que passa Pierre Perrault, Jean Rouch e outros?

\section{Referências}

BLANCHOT, M. A Comunidade Inconfessável. Brasília: Ed. UnB, 2013.

CANGUILHEM, G. O normal e o patológico. Rio de Janeiro: Ed. GEN/Forense Universitária, 2015.

COSTA, P. Un mirlo dourado, un ramo de flores y una cuchara de plata: conversación com Pedro Costa, collage de Andy Rector, documentos. Barcelona: Ed. Progimag, 2011.

DELEUZE, G. Bartleby, ou a fórmula. In: Crítica e Clínica. São Paulo: Ed. 34, 2011.

DELEUZE, G. A imagem-movimento. Cinema I. Lisboa: Ed. Assírio \& Alvim, 2009.

DELEUZE, G. A imagem-tempo. Cinema II. São Paulo: Ed. Brasiliense, 2005.

DELEUZE, G; GUATTARI, F. 1730 - Devir-intenso, devir-animal, devir-imperceptível... In: Mil Platôs: capitalismo e esquizofrênia. v. 2. São Paulo: Ed. 34, 2012.

LAPOUJADE, D. As existências mínimas. Ed. N-1. São Paulo, 2017.

\section{Referências fílmicas}

JUVENTUDE em Marcha. Direção Pedro Costa. Portugal. Ventura Film; Contracosta produções; Les films de L'etranger; Radio Televisão Porguesa (RTP). 1 DVD. (156 min.). 